\title{
Improving Wood Resistance to Decay by Nanostructured ZnO-Based Treatments
}

\author{
Maduka L. Weththimuni $\mathbb{D D}^{1}{ }^{1}$ Doretta Capsoni, ${ }^{1}$ Marco Malagodi $\mathbb{D}^{2,3}$ \\ and Maurizio Licchelli (iD) ${ }^{1,2}$ \\ ${ }^{1}$ Dipartimento di Chimica, Università di Pavia, via Taramelli 12, 27100 Pavia, Italy \\ ${ }^{2}$ Laboratorio Arvedi di Diagnostica Non-Invasiva, CISRiC, Università di Pavia, Via Bell'Aspa 3, 26100 Cremona, Italy \\ ${ }^{3}$ Dipartimento di Musicologia e Beni Culturali, Università di Pavia, Corso Garibaldi 178, 26100 Cremona, Italy
}

Correspondence should be addressed to Maduka L. Weththimuni; madukalankani.weththimuni@unipv.it and Maurizio Licchelli; maurizio.licchelli@unipv.it

Received 4 November 2018; Revised 14 March 2019; Accepted 9 April 2019; Published 2 May 2019

Academic Editor: Mohamed Bououdina

Copyright ( 2019 Maduka L. Weththimuni et al. This is an open access article distributed under the Creative Commons Attribution License, which permits unrestricted use, distribution, and reproduction in any medium, provided the original work is properly cited.

In this study, the maple wood surface was coated with nanostructured zinc oxide, grown on the surface by using a hydrothermal process, and furtherly treated with shellac varnish. Samples obtained both after ZnO treatment and after the final varnish application were characterized by different techniques, i.e., X-ray diffraction (XRD), scanning electron microscopy combined with energy-dispersive X-ray spectroscopy (SEM-EDS), micro-FTIR with attenuated total reflectance ( $\mu$-ATR-FTIR), chromatic variation measurements, and contact angle determinations. Analytical results showed that the wood surface was covered by quite a homogeneous array of inorganic nanoparticles and that the natural resin forms a regular film over the $\mathrm{ZnO}$ nanostructures. An accelerated aging test was used to evaluate the protecting effectiveness of the treatments towards UV-induced decay of wood material. After the test, wood treated with $\mathrm{ZnO}$ and with the shellac/ $\mathrm{ZnO}$ combination underwent a considerably lower chromatic change if compared to the untreated wood, suggesting an enhanced resistance of the treated maple to the decay due to light exposition. The presence of nanostructured $\mathrm{ZnO}$ protects from decay not only the wood substrate but also the shellac film. A microbiology test showed that growth of fungal species, e.g., common mold, is prevented on the wood surface treated with $\mathrm{ZnO}$ or with shellac/ZnO, indicating that the nanostructured zinc oxide also provides an effective protection from biodeterioration. The coating obtained by consecutive application of nanosized $\mathrm{ZnO}$ particles and shellac varnish combines the excellent aesthetical features and water repellence of the traditional finish with the protecting effectiveness of the nanostructured inorganic component.

\section{Introduction}

Study of novel methods for the durability enhancement of wood artifacts currently represents an important research topic [1]. Wood is an organic material that undergoes different degradation processes due to environmental agents (e.g., solar radiation, water, and biodeteriogens) [2].

Absorption of solar light, particularly of the ultraviolet (UV) component, is mainly responsible for wood photodegradation induced by different photolytic and/or photooxidative reactions [3-5]. Therefore, when exposed to solar light, wood undergoes a range of decay processes from the simple change of esthetic appearance (e.g., surface discoloration) to a severe decrease in the mechanical properties [5-8].

Due to the general hydrophilic character of its main components (cellulose, hemicellulose, and lignin), wood can adsorb water both as vapour and as liquid, establishing an equilibrium with the air moisture. The presence of water can be merely related to shrinkage/swelling phenomena induced by absorption/desorption processes but also favors hydrolytic reactions and the action of biodeteriogens (e.g., bacteria, fungi, and xilophages), particularly when the moisture content of the wood exceeds the fiber saturation point. 
Owing to the various natures of the more common decay processes affecting wood, the development of effective treatments for a whole preservation of wood artifacts still represents a challenge from a scientific and technological point of view.

Some important studies concerning the application of nanomaterials to the conservation of wood have been reported since the last decade [5,9-11]. In particular, several papers describe the behavior of novel nanocomposites in which nanosized inorganic compounds (e.g., $\mathrm{SiO}_{2}, \mathrm{ZnO}$, and $\mathrm{TiO}_{2}$ ) are dispersed in the polymeric matrixes of conventional coatings $[10,12,13]$.

In most cases, the nanoparticles enhance the performance of the protective treatments in terms of coated wood durability (resistance to photodegradation, fungal growth, staining, and discoloration) as well as of its mechanical properties (e.g., enhanced scratch resistance). [14-19].

Other studies deal with the deposition of nanometric inorganic particles on wood surfaces and show that unique properties (e.g., photostability, antifungal capability, and moisture protection) can be obtained by similar treatments [20-23].

$\mathrm{ZnO}$ is a semiconductor that has found wide application in the optics and electronics areas [24-27]. Moreover, it has been used as UV adsorber and protecting agent for different materials, including cellulosic fibers, in order to improve the resistance to light-induced decay $[28,29]$.

Several studies have also pointed out that nanostructured $\mathrm{ZnO}$ displays an effective antibacterial and antifungal activity that is strictly correlated with the small size of particles and the consequent large specific surface area [30-34]. The mechanism of the antimicrobial effect is still controversial, and different hypotheses have been reported till now [34]. Due to their small size, $\mathrm{ZnO}$ nanoparticles could interact with the microbial cell surface or could enter the cell wall of microbes and interfere with the metabolic processes through the release of $\mathrm{Zn}^{2+}$ ions or the production of intracellular reactive oxygen species (ROS) [34]. Cellulosic materials such as textile fibers and wood can be used as substrate to grow nanosized zinc oxide crystals in order to prepare hybrid materials displaying enhanced resistance to photodegradation as well as to decay induced by fungi and/or insects [5, 20, 35-39]. Therefore, nanostructured $\mathrm{ZnO}$ can be considered a promising, cost-effective, and environmentally friendly preservative for wood. Additional investigations about its protecting ability, even in combination with other treatments for wood, are desirable in view of possible practical applications.

Surface treatments of wooden objects (e.g., furniture, musical instruments) are often required to provide not only a general protection from environmental decay agents, but also a satisfactory aesthetical appearance.

The application of surface coatings still represents the most common practice for wood protection. Coatings for wood can be based on synthetic polymers (e.g., polyurethanes, polyesters, and polyacrylates) or on more traditional materials of natural origin (resins, oils, and waxes) $[15,40]$.

Shellac is a resinous material of animal origin obtained from the secretions of Lac insects (e.g., Kerria lacca, Laccifer lacca), hosted as parasites by some trees growing in eastern
Asia $[41,42]$. Shellac has been widely used since the $17^{\text {th }}$ century to varnish and protect the surface of fine wood artifacts due to some peculiar properties such as low toxicity, good film-forming ability, high adhesion to the wood surface, and excellent aesthetical appearance $[15,42]$. It is still considered as one of the most elegant finishes for furniture, and it is one of the most used varnishes for string musical instruments.

A few years ago, we studied the effect of $\mathrm{ZnO}$ nanoparticles dispersed in shellac coatings in order to improve the resistance of the coating (and of the treated wood) to the decay induced by exposition to light [42].

In this work, we have studied the protecting effectiveness of nanostructured $\mathrm{ZnO}$ when deposited on maple wood, in combination with shellac coatings. In particular, we investigated the resistance of treated wood specimens to mold growth, in comparison with untreated maple. The resistance to light-induced decay was tested by examining the surface of treated and untreated maple after accelerated ageing under UV illumination.

\section{Materials and Methods}

Analytical grade sodium hydroxide $(\mathrm{NaOH})$, ethanol $(95 \%$ EtOH), zinc acetate dihydrate $\left(\mathrm{ZnC}_{4} \mathrm{H}_{6} \mathrm{O}_{4} \cdot 2 \mathrm{H}_{2} \mathrm{O}\right)$, zinc nitrate hexahydrate $\left(\mathrm{Zn}\left(\mathrm{NO}_{3}\right)_{2} \cdot 6 \mathrm{H}_{2} \mathrm{O}\right)$, and hexamethylenetetramine were supplied by Sigma-Aldrich and were used as received.

Dewaxed natural shellac (food quality shellac) was purchased from Kremer Pigmente and used without any further purification. It was dissolved in ethanol solution in order to obtain a standard shellac solution $(100 \mathrm{~g} / \mathrm{L})$.

Maple wood specimens $(2 \times 2 \times 0.5 \mathrm{~cm})$ were kindly provided by Civica Scuola di Liuteria (Milan, Italy). Prior to use, they were smoothed by abrasive paper sheets (progressively from 400 to 1000 mesh) similar to the real cases.

Nanostructured $\mathrm{ZnO}$ was "grown" on wood surface using a two-step process consisting of seed deposition and crystal growth, according to literature methods $[5,43]$.

2.1. Deposition of $\mathrm{ZnO}$ Seeds on the Wood Surface. At first, standard solutions of $\mathrm{NaOH}(0.03 \mathrm{M})$ and of zinc acetate dihydrate $(0.01 \mathrm{M})$ were prepared in ethanol. $\mathrm{NaOH}$ solution $(133 \mathrm{~mL})$ was slowly added to a Pyrex glass bottle containing zinc acetate solution $(200 \mathrm{~mL})$ at about $60^{\circ} \mathrm{C}$, and the resulting mixture was stirred for 3 hours to form a transparent solution containing $\mathrm{ZnO}$ nanoparticles, which is stable at least for 20 days. Maple wood specimens were immersed in this solution at room temperature for one hour in order to obtain the deposition of $\mathrm{ZnO}$ (dipcoating process). Thereafter, the specimens were heated in an oven at $100^{\circ} \mathrm{C}$ for 3 hours. The above described process was repeated 10 times. After this treatment, specimens were then used for subsequent $\mathrm{ZnO}$ growth under hydrothermal conditions.

2.2. Growth of Nanosized ZnO Crystals on the Wood Surface. For this purpose, standard aqueous solutions of hexamethylenetetramine (HMTA, $0.02 \mathrm{M}$ ) and zinc nitrate hexahydrate 
$(0.02 \mathrm{M})$ were prepared. The seed-coated wood specimens were immersed in an aqueous solution obtained by mixing an equal amount of the abovementioned standard solutions, and temperature was maintained at about $90^{\circ} \mathrm{C}$ (hydrothermal reaction) for 6 hours. The resulting wood specimens were properly rinsed with deionized water, and then they were dried in an oven at $60^{\circ} \mathrm{C}$ for 3 hours. Specimens obtained by this procedure were labeled as $\mathrm{W}+\mathrm{ZnO}$.

2.3. Application of Shellac Varnish. A group of wood specimen-coated nanostructured $\mathrm{ZnO}$ were treated with shellac solution $(100 \mathrm{~g} / \mathrm{L}$ in ethanol) by brushing and were labeled as $\mathrm{W}+\mathrm{ZnO}+\mathrm{SH}$. Shellac was applied two times, according to perpendicular directions (the brush direction of second application was perpendicular to the first one).

Moreover, nine specimens of untreated wood were treated only with shellac in order to compare the performances with the combined treatment and were labeled as $\mathrm{W}+\mathrm{SH}$.

2.4. General Procedures. Optical microscope observations of wood specimens were performed by a light-polarized microscope Olympus BX51TF, equipped with visible (Olympus TH4-200) and UV (Olympus U-RFL-T) lamps or by a Dino-Lite AM 413TFVW-A digital microscope.

Scanning electron microscopy (SEM) and energydispersive X-ray (EDS) analyses were performed at the Arvedi Laboratory, CISRiC-Università di Pavia, by using a Tescan FE-SEM (MIRA3 XMU series) and EDAX instruments. The SEM apparatus was equipped with a Schottky field emission source, operating in both low and high vacuum. Samples were previously gold-sputtered using a Cressington sputter coater 208HR.

X-ray powder diffraction (XRD) measurements were taken using a Bruker D5005 diffractometer with the $\mathrm{CuK} \alpha$ radiation, graphite monochromator, and scintillation detector.

Micro-FTIR spectra were measured at Arvedi Laboratory, CISRiC-Università di Pavia, by a Nicolet iN10 Thermo Fischer $\mu \mathrm{FT}$-IR spectrometer in attenuated total reflectance mode (ATR, germanium crystal).

Colour measurements were taken by using a Konica Minolta CM-2600d spectrophotometer: $L^{*}, a^{*}$, and $b^{*}$ coordinates of the CIELAB space and the overall chromatic variations $\Delta E^{*}$ were determined according to the UNI EN 15886 protocol. [44]

Surface wettability was evaluated by water contact angle measurements (by a CAM 200 apparatus, KSV Instruments) in order to analyze the hydrophobic behavior of coated wood samples $(\mathrm{W}+\mathrm{SH}, \mathrm{W}+\mathrm{ZnO}$, and $\mathrm{W}+\mathrm{ZnO}+\mathrm{SH})$, and results were compared with untreated wood.

Five measurements were taken on each specimen area for colorimetric and contact angle determinations, and all the given results are average values.

2.5. Testing Methods. The examined wood samples (UW, W $+\mathrm{SH}, \mathrm{W}+\mathrm{ZnO}$, and $\mathrm{W}+\mathrm{ZnO}+\mathrm{SH}$ ) were artificially weathered by using an irradiation system (Helios Italquartz, Milan) equipped with a couple of mercury lamps (15 W) for 520 hours. During the irradiation, temperature and relative humidity in the chamber were controlled at $25^{\circ} \mathrm{C}$ and $30 \%$, respectively. For all experiments, the specimens were removed from the chamber after $280 \mathrm{~h}$ and analyzed by measuring chromatic variations.

Antifungal performance of the surface treatments was evaluated by applying a procedure reported in literature [43]. Both control (UW) and treated samples $(\mathrm{W}+\mathrm{ZnO}$ and $\mathrm{W}+\mathrm{ZnO}+\mathrm{SH}$ ) were water saturated (by immersion), and then they were placed in desiccators where relative humidity and temperature were controlled at $95 \pm 2 \%$ and $24 \pm 1^{\circ} \mathrm{C}$, respectively. The desiccators were kept in a common laboratory with normal illumination in the daytime and a dark break at night for 40 days. Presence of molds on wood specimens was investigated every day.

\section{Results and Discussions}

3.1. Deposition of Nanostructured $\mathrm{ZnO}$ and Application of Shellac on Wood Surface. The production of $\mathrm{ZnO}$ nanostructures (e.g., nanorods, nanobelts, and nanorings), by hydrothermal process on different substrates has been widely investigated [5, 43, 45-49]. In particular, several studies reported the effects of the experimental conditions (e.g., species concentration, $\mathrm{pH}$, and temperature) on the features of the nano-objects (e.g., shape, pattern, and homogeneity) [50-54].

In the present work, the growth of $\mathrm{ZnO}$ nanostructures on the wood surface was obtained by a two-step process, adapted from a well-known literature procedure $[5,43,55]$. In the first step, $\mathrm{ZnO}$ nanoparticles were easily prepared from zinc acetate in ethanol under basic conditions [56]. Then, $\mathrm{ZnO}$ nanocrystals were deposited on the maple surface by the dip-coating process, performing repeated immersions of specimens into a formerly prepared solution of $\mathrm{ZnO}$ nanoparticles. Adhesion of crystal seeds was ensured by heating at $100^{\circ} \mathrm{C}$ the coated specimens between depositions [55]. It has been hypothesized that in similar conditions the adhesion of $\mathrm{ZnO}$ seeds (and furtherly of nanostructures) on the wood surface is favored by stable bonds at the wood- $\mathrm{ZnO}$ interphase involving $\mathrm{Zn}^{2+}$ ions and chelating groups of the lignin structure (e.g., guaiacol), which can partially replace oxide (or hydroxide) in the zinc(II) coordination shell [57].

In the second step, the hydrothermal growth of $\mathrm{ZnO}$ on the deposited seeds was carried out by immersion of maple specimens in aqueous solution containing zinc(II) nitrate and hexamethylenetetramine (HMTA). The experimental conditions were properly set in order to favor a slow and controlled growth of nano-objects, as described in literature [58, 59].

Shellac was applied on the surface of wood specimens (both plain and $\mathrm{ZnO}$-treated maple) by brush according to a conventional procedure [15]. Application on the $\mathrm{ZnO}$ coated surface was particularly gentle in order to avoid any mechanical removal of nanostructured material. It can be supposed that shellac films strongly adhere to the $\mathrm{ZnO}$ deposited on wood, as an interaction involving carboxylate groups of the natural resin and $\mathrm{Zn}^{2+}$ can take place.

3.2. Study of Treated Wood Surface. Treated wood specimens were examined by different experimental techniques in order 
TABLE 1: Changes of chromatic properties determined for treated wood specimens after different treatments. Contact angle values for all the considered specimens are also reported. Standard deviation values are given in brackets.

\begin{tabular}{|c|c|c|c|c|c|}
\hline Samples & $\Delta L^{*}$ & $\Delta a^{*}$ & $\Delta b^{*}$ & $\Delta E^{*}$ & $\alpha\left(^{\circ}\right)$ \\
\hline UW & - & - & - & - & $56( \pm 3)$ \\
\hline $\mathrm{W}+\mathrm{ZnO}$ & $-9.9( \pm 0.4)$ & $0.5( \pm 0.3)$ & $1.7( \pm 1.2)$ & $10( \pm 1)$ & $68( \pm 6)$ \\
\hline $\mathrm{W}+\mathrm{SH}$ & $-4.1( \pm 1.9)$ & $1.6( \pm 0.8)$ & $6.5( \pm 0.6)$ & $8( \pm 2)$ & $88( \pm 5)$ \\
\hline $\mathrm{W}+\mathrm{ZnO}+\mathrm{SH}$ & $-11.6( \pm 1.6)$ & $0.9( \pm 0.2)$ & $1.8( \pm 1.3)$ & $12( \pm 1)$ & $95( \pm 4)$ \\
\hline
\end{tabular}

to investigate the properties of wood surface after the zinc oxide deposition (specimens $\mathrm{W}+\mathrm{ZnO}$ ) and after the combined treatment $(\mathrm{W}+\mathrm{ZnO}+\mathrm{SH})$, as well as the composition of the resultant coatings. All the determinations were performed by properly comparing the results obtained from treated specimens with the untreated wood (UW) or with wood varnished with plain shellac $(\mathrm{W}+\mathrm{SH})$.

3.2.1. Colour and Contact Angle Measurements. Table 1 summarizes the variations of chromatic coordinates and the overall colour changes (expressed as $\Delta E^{*}$ ) determined after any of the considered treatments performed on maple specimens.

All treatments induce a considerable variation of the chromatic properties of maple surface with $\Delta E^{*}$ values ranging between 8 and 12. The changes in chromatic coordinates, particularly the decrease in $L^{*}$, indicate that the presence of $\mathrm{ZnO}$ (both in $\mathrm{W}+\mathrm{ZnO}$ and $\mathrm{W}+\mathrm{ZnO}+\mathrm{SH}$ ) mainly affects the lightness of wood specimens likely due to surface modification induced by the nanosized particles. The application of plain shellac moderately affects both $L^{*}$ and $b^{*}$ (increase of the yellow component), in accordance with previous observations [42].

Shellac-based coatings are expected to provide a moderate protection from water and environmental humidity. The hydrophobic behavior of the investigated treatments was evaluated by carrying out static contact angle $(\alpha)$ measurements on the surface of both untreated treated maples. The experimental contact angle values are reported in Table 1. The original wood (UW) displays the expected hydrophilic character $\left(\alpha=56^{\circ}\right)$, which is affected only to a moderate extent by the $\mathrm{ZnO}$ treatment $\left(\mathrm{W}+\mathrm{ZnO}, \alpha=68^{\circ}\right)$. Contact angle measurements confirm the moderately hydrophobic character of the native shellac ( $\left.\mathrm{W}+\mathrm{SH}, \alpha=88^{\circ}\right)$, which is preserved even in the case of the combined treatment $\left(\mathrm{W}+\mathrm{ZnO}+\mathrm{SH}, \alpha=95^{\circ}\right)$. The small increase in the contact angle value measured on $\mathrm{W}+\mathrm{ZnO}$ can be ascribed to the surface modification induced by inorganic nanostructures. In fact, hydrophobicity enhancement can be obtained by increasing surface roughness at the nanoscale level [60]. Specimens treated with shellac display a moderate water-repellent character which can be mainly ascribed to the organic coating. It should be noted that the apparent increase of $\alpha$ in $\mathrm{W}+\mathrm{ZnO}$ $+\mathrm{SH}$, when compared to $\mathrm{W}+\mathrm{SH}$, is poorly significant if standard deviation values are taken into account (see Table 1).

3.2.2. X-Ray Diffraction Experiments. The X-ray diffraction patterns of the analyzed samples are shown in Figure 1. As expected, no clear peaks ascribable to pure crystalline phases are observed in the case of untreated wood. The patterns

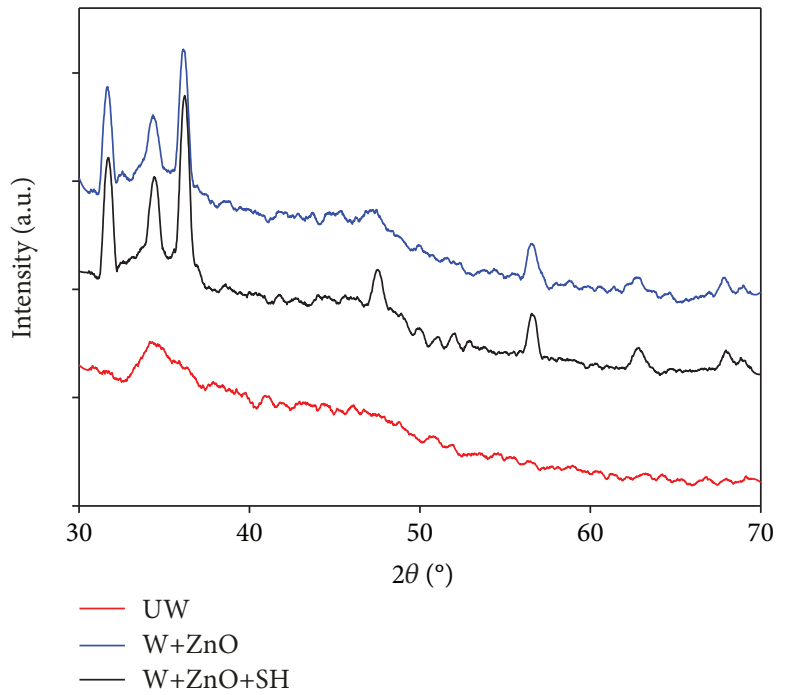

FIGURE 1: XRD patterns determined on untreated and coated wood specimens.

corresponding to $\mathrm{W}+\mathrm{ZnO}$ and $\mathrm{W}+\mathrm{ZnO}+\mathrm{SH}$ indicate the presence of a new crystalline phase on the wood surface. In both samples, the diffraction peaks can be ascribed to the $\mathrm{ZnO}$ structure and particularly indexed to zincite (wurtzite hexagonal structure), according to the JCPDS data base (No. 36-1451). The diffraction pattern obtained from $\mathrm{W}+\mathrm{ZnO}+\mathrm{SH}$, which is very similar to that of $\mathrm{W}+\mathrm{ZnO}$, demonstrates that the crystalline structure of nanosized $\mathrm{ZnO}$ deposited on the maple surface is still preserved even after application of shellac varnish.

3.2.3. SEM-EDS Studies. Surfaces of treated wood specimens were observed by scanning electron microscopy experiments in order to have a better insight on the microscopic properties (i.e., particle size, morphology, and homogeneity) of the coating layers, while information about their elemental composition was gained by taking energydispersive X-ray spectroscopy (EDS) measurements.

SEM micrographs taken on all the treated wood samples $(\mathrm{W}+\mathrm{ZnO}, \mathrm{W}+\mathrm{SH}$, and $\mathrm{W}+\mathrm{ZnO}+\mathrm{SH})$ are reported in Figure 2. A micrograph taken on the untreated maple is also shown for comparison. The wood surface after treatment by the hydrothermal process appears covered with a dense and quite uniform layer of nanosized particles (Figure 2(c)). EDS analysis confirms that $\mathrm{Zn}$ is the main elemental component (Figure 2(d)). Other $\mathrm{ZnO}$ structures displaying different shapes (e.g., hexagonal prism) and 


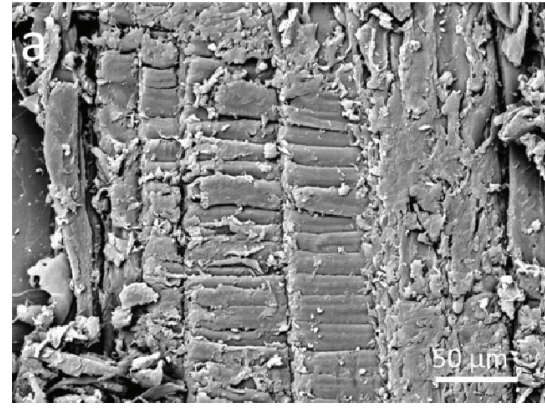

(a)

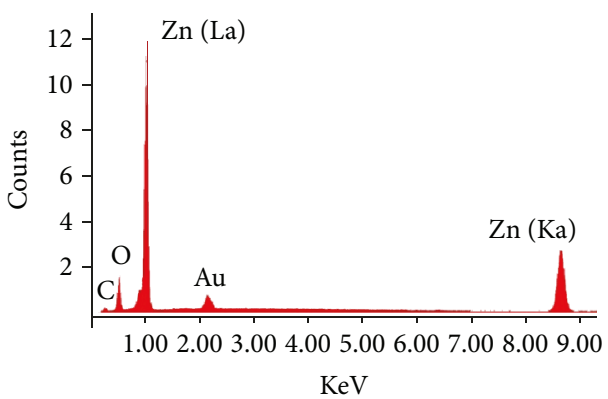

(d)

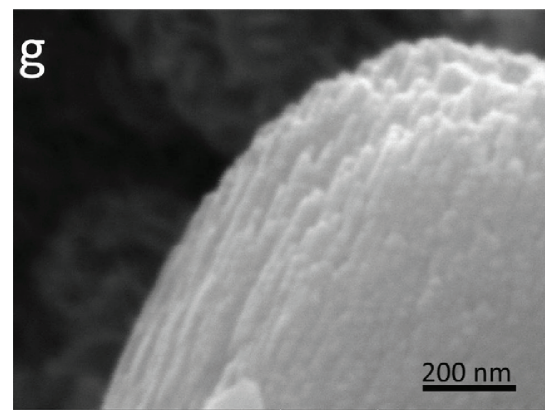

(g)

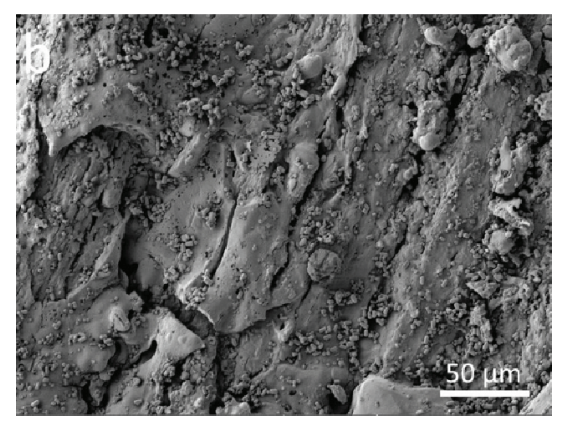

(b)

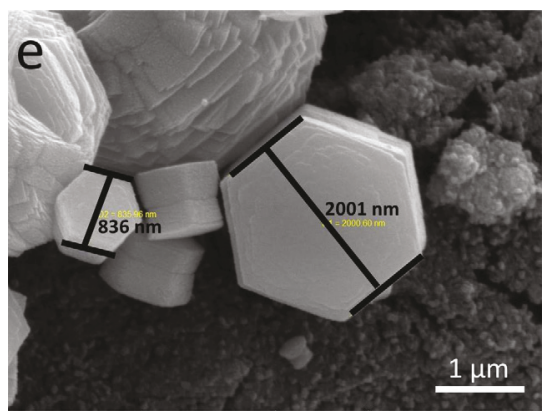

(e)

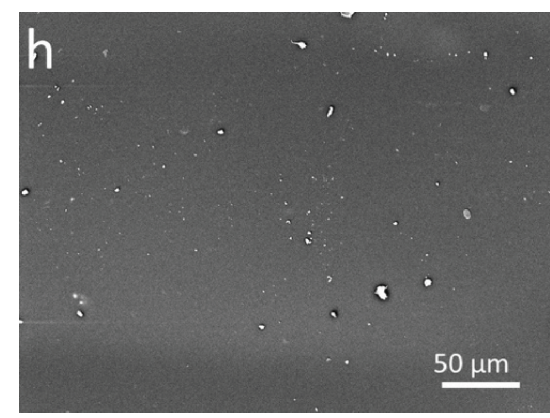

(h)

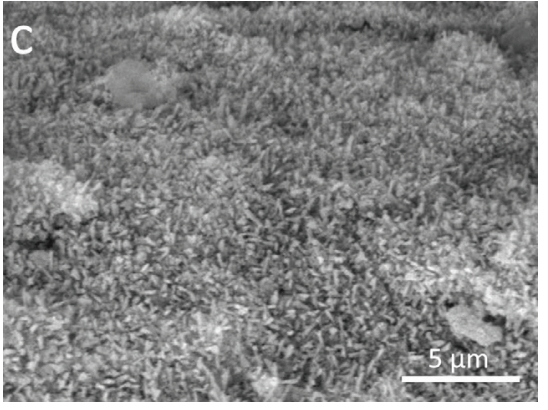

(c)

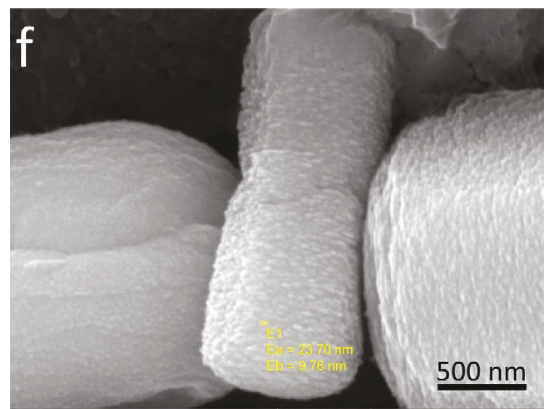

(f)

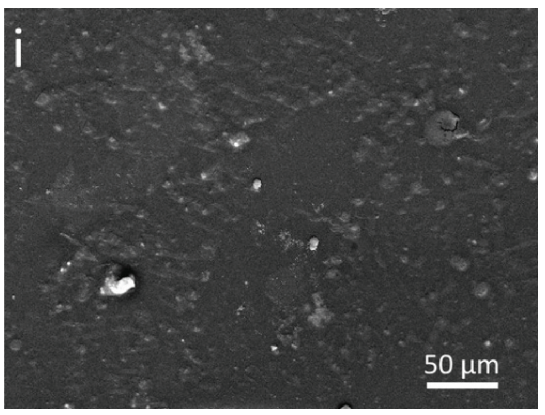

(i)

FIGURE 2: SEM-EDS experiments performed on treated and untreated wood surface: SEM micrographs of (a) untreated maple; (b) and (c) $\mathrm{W}+\mathrm{ZnO}$ at different magnification; (d) EDS spectrum measured on the ZnO-coated wood surface; (e), (f), and (g) ZnO particles displaying different shapes and sizes at increasing magnification; (h) $\mathrm{W}+\mathrm{SH}$; (i) $\mathrm{W}+\mathrm{ZnO}+\mathrm{SH}$.

sizes have been also observed on some areas of the treated surface (Figures 2(e) and 2(f)). Hexagonal prism shape has been often observed in previous work concerning nanostructured zinc oxide and ascribed to wurtzite [5]. The presence of the wurtzite crystalline phase is also in accordance with XRD outcomes. Images at higher magnification (Figure $2(\mathrm{~g})$ ) show that these larger particles are really made by an array of nanosized crystalline subunits, according to a bundle-shaped packing structure. The diameter and length of the condensed subunits can be estimated to be $10-24 \mathrm{~nm}$ and $1-2 \mu \mathrm{m}$, respectively. The surface of $\mathrm{W}+\mathrm{SH}$ is regular and smooth, suggesting that the coating layer has been uniformly applied on wood substrate (Figure 2(h)). Similarly, shellac forms a homogeneous layer on $\mathrm{W}+\mathrm{ZnO}+\mathrm{SH}$ specimen, which covers the underlying nanostructured $\mathrm{ZnO}$ (Figure 2(i)).
3.2.4. FTIR Investigations. The chemical properties of the wood surface after the different treatments were investigated by micro-ATR-FTIR analyses. Spectra obtained from measurements on all the considered specimens, including UW, are reported in Figure 3.

The FTIR spectrum of untreated maple displays the typical set of bands due to the absorption of both carbohydrate components (cellulose and hemicellulose) and lignin of wood $[5,61]$. On the other hand, the peaks corresponding to the absorption of wood components almost completely disappear in the spectrum of $\mathrm{W}+\mathrm{ZnO}$, confirming that the maple surface is quite homogeneously covered by a layer of crystalline nanostructured zinc oxide, in accordance with the results of XRD and SEM-EDS measurements.

The FTIR spectrum of $\mathrm{W}+\mathrm{SH}$ exhibits the characteristic bands due to the natural resin (Figure 3) $[42,62,63]$. The 


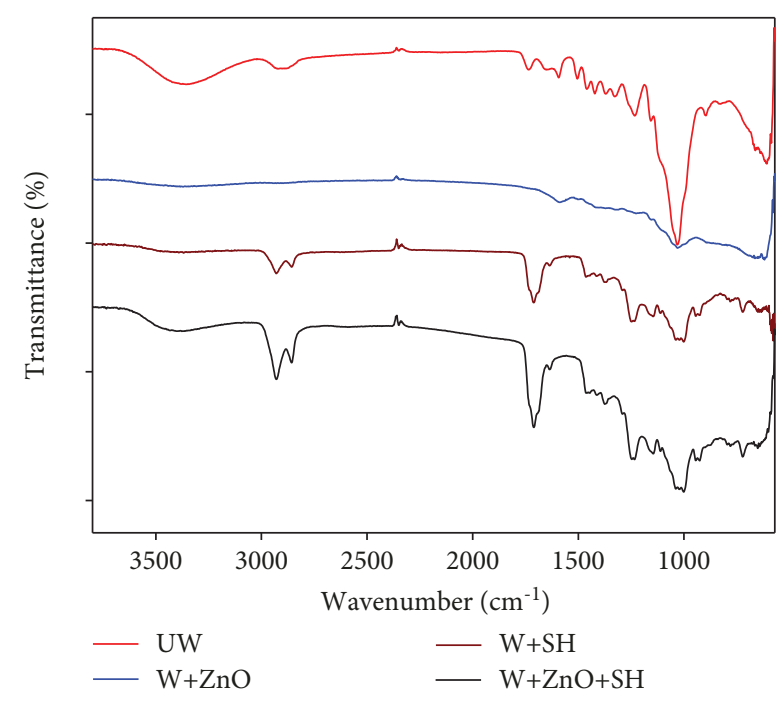

Figure 3: Micro-ATR-FTIR spectra of untreated and treated wood specimens.

broad band in the $3600-3100 \mathrm{~cm}^{-1}$ range is attributed to the stretching of different $\mathrm{OH}$ functional groups, e.g., carboxylic and alcoholic groups (Figure 3). The two peaks at around 2850 and $2975 \mathrm{~cm}^{-1}$ are ascribed to the $\mathrm{C}-\mathrm{H}$ stretching vibrations of $-\mathrm{CH}_{2}$ and $-\mathrm{CH}_{3}$ groups, respectively, while the absorptions corresponding to bending $\mathrm{C}-\mathrm{H}$ of the same groups can be found at around 1450 and $1390 \mathrm{~cm}^{-1}$, respectively. In addition, the strong peak in the $1700-1800 \mathrm{~cm}^{-1}$ range is the characteristics of the carbonyl group $(\mathrm{C}=\mathrm{O})$ in carboxylic acid and ester functions.

Peaks observed in the $1250-1000 \mathrm{~cm}^{-1}$ region can be mainly ascribed to different vibration modes of $\mathrm{C}-\mathrm{O}$ and C-C bonds $[62,63]$.

As the spectrum measured on the surface of $\mathrm{W}+\mathrm{ZnO}+\mathrm{SH}$ specimen displays the same absorption bands of the wood varnished with plain shellac (Figure 3), we can suppose that the final coating forms a homogeneous layer covering the nanostructured $\mathrm{ZnO}$.

3.3. UV Ageing Test. As mentioned above, exposition of wood to light, particularly to UV irradiation, may induce even drastic decomposition of its components (i.e., lignin and cellulose) as well as of possible coatings (e.g., coatings) that are applied to its surface. An accelerated ageing test was performed in order to assess the resistance of $\mathrm{ZnO}$-treated specimens to the UV-induced degradation, with respect to the untreated wood and to the wood treated with plain shellac. Therefore, specimens labeled as $\mathrm{UW}, \mathrm{W}+\mathrm{SH}, \mathrm{W}+\mathrm{ZnO}$, and $\mathrm{W}+\mathrm{ZnO}+\mathrm{SH}$ were irradiated with a UV lamp up to $520 \mathrm{~h}$ and their surface examined in the middle and at the end of the artificial weathering process. Taking into account that colour changes can be considered as direct and visible expression of decay occurred to wood components, chromatic coordinates were measured on the surface of the examined specimens in the course and at the end of the irradiation time.
Variations of $L^{*}, a^{*}$, and $b^{*}$ chromatic coordinates observed after the UV-induced ageing are collected in Table 2. Figure 4 reports the values of overall chromatic changes, expressed as $\Delta E^{*}$, determined after 280 and 520 hours of UV irradiation for all the considered specimens.

After artificial ageing, both untreated wood and wood treated with plain shellac underwent considerable chromatic changes ( $\Delta E^{*} \sim 9$ and 15 after 280 and $520 \mathrm{~h}$, respectively) mainly due to the decrease in lightness $\left(L^{*}\right)$ and to the increase in the $b^{*}$ coordinate, which is related to the blue/yellow change. As a consequence, after UV irradiation, UW and $\mathrm{W}+\mathrm{SH}$ specimens appear darker and more yellowish, if compared to their pristine aspect (i.e., before ageing). On the contrary, distinctly lower values of $\Delta E^{*}$ were determined for $\mathrm{W}+\mathrm{ZnO}(0.8 \pm 0.6$ and $1.9 \pm 0.3$ after 280 and $520 \mathrm{~h}$, respectively) and $\mathrm{W}+\mathrm{ZnO}+\mathrm{SH}$ specimens $(4.6 \pm 0.2$ and 4.4 \pm 0.5 after 280 and $520 \mathrm{~h}$, respectively). Although the irradiation has been stopped after $520 \mathrm{~h}$, the values of $L^{*}, a^{*}$, and $b^{*}$ coordinates collected in the course of UV irradiation clearly indicate that chromatic changes and, of consequence, the related surface damage degree increase with the light exposition time (see Table 2). In any case, the changes observed on specimens containing $\mathrm{ZnO}$ are significantly lower than on UW and $\mathrm{W}+\mathrm{SH}$ specimens, suggesting that the presence of nanostructured $\mathrm{ZnO}$ on the surface of maple reduces (if not prevents) the effects of the UV-induced decay both on the wood and on the shellac film. This behavior can be ascribed to the well-known efficiency of $\mathrm{ZnO}$ as UV absorber, particularly when it is applied as nanosized particles [10-13]. On the other hand, zinc oxide can induce the formation of reactive oxygen species, ROS, particularly under light irradiation [64, 65]. In principle, those radical species could promote decay processes of wood support and/or shellac matrix. As a matter of fact, this "side effect" has been observed nor in the present work nor in previous papers describing the application of nanosized $\mathrm{ZnO}$ on organic substrates or dispersed in organic coatings [10-15]. It would suggest that the action of $\mathrm{ZnO}$ as $\mathrm{UV}$ absorber and protecting agent prevails over the possible effects generated by radical species.

Contact angles were also measured on the surface of wood specimens after UV aging (see Table 2) and compared to the corresponding values obtained before aging (see Table 1) in order to assess possible variations of hydrophilic/hydrophobic properties. It should be noted that after $520 \mathrm{~h}$ exposition to UV lamp, it was not possible to carefully measure the $\alpha$ value for UW, as water droplets deposited on its surface were readily absorbed. An increase in the hydrophilic character of wood, if compared to unaged UW, could be due to the formation of more polar groups on the maple surface promoted by light-induced oxidation processes. A moderate decrease in the $\alpha$ value was also observed for $\mathrm{W}+\mathrm{SH}$, following its irradiation with UV lamp. It can be ascribed to structural modifications of the organic coating that undergoes a progressive decay under prolonged exposition to UV light, with a consequent loss of the protective properties originally displayed by shellac. On the contrary, UV ageing did not affect the water-repellent properties of both $\mathrm{W}+\mathrm{ZnO}$ 
TABLE 2: Variations of chromatic coordinates of different wood specimens after UV ageing. The values obtained by comparing $L^{*}, a^{*}$, and $b^{*}$ of the artificially aged samples and the same coordinates of the corresponding samples before ageing. Contact angle values for all the considered specimens after aging are also reported. Standard deviation values are given in brackets.

\begin{tabular}{|c|c|c|c|c|c|c|c|}
\hline \multirow{2}{*}{ Samples } & \multicolumn{3}{|c|}{$280 \mathrm{~h}$} & \multicolumn{4}{|c|}{$520 \mathrm{~h}$} \\
\hline & $\Delta L^{*}$ & $\Delta a^{*}$ & $\Delta b^{*}$ & $\Delta L^{*}$ & $\Delta a^{*}$ & $\Delta b^{*}$ & $\alpha\left(^{\circ}\right)$ \\
\hline UW & $-3.9( \pm 2.1)$ & $1.4( \pm 0.9)$ & $7.9( \pm 0.3)$ & $-6.8( \pm 2.4)$ & $3.5( \pm 0.8)$ & $12.6( \pm 0.3)$ & - \\
\hline $\mathrm{W}+\mathrm{ZnO}$ & $-0.4( \pm 0.2)$ & $0.4( \pm 0.1)$ & $-0.4( \pm 0.8)$ & $-0.6( \pm 0.4)$ & $0.9( \pm 0.3)$ & $0.5( \pm 0.1)$ & $70( \pm 5)$ \\
\hline $\mathrm{W}+\mathrm{SH}$ & $-5.3( \pm 1.4)$ & $4.2( \pm 1.1)$ & $7.9( \pm 2.1)$ & $-6.0( \pm 2.6)$ & $5.7( \pm 1.6)$ & $11.8( \pm 1.6)$ & $74( \pm 2)$ \\
\hline $\mathrm{W}+\mathrm{ZnO}+\mathrm{SH}$ & $-3.4( \pm 0.2)$ & $2.3( \pm 0.1)$ & $2.3( \pm 0.2)$ & $-2.3( \pm 0.3)$ & $2.5( \pm 0.6)$ & $2.8( \pm 0.6)$ & $100( \pm 7)$ \\
\hline
\end{tabular}

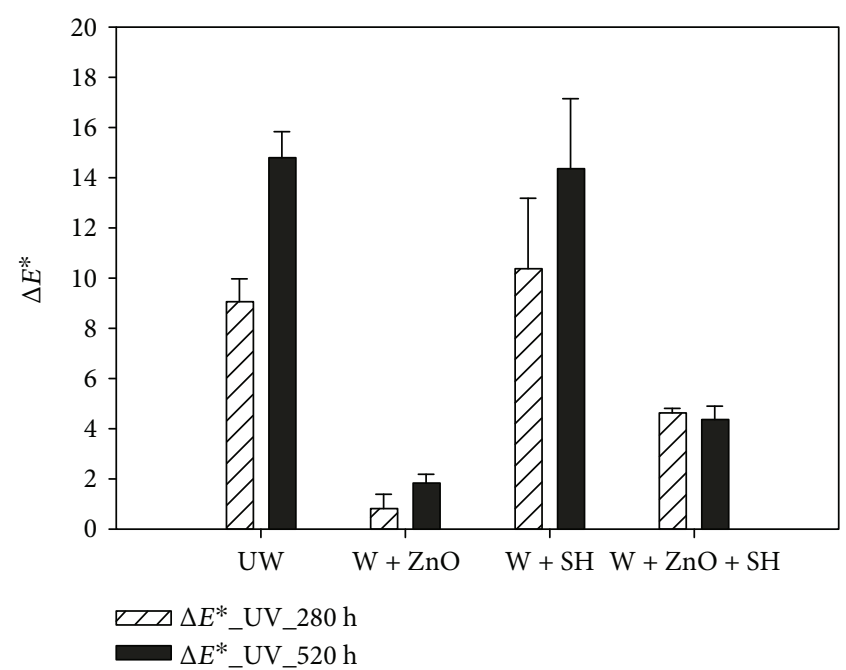

FIGURE 4: Overall chromatic variation of different wood specimens during and at the end of UV irradiation.

and $\mathrm{W}+\mathrm{ZnO}+\mathrm{SH}$, as $\alpha$ values determined before and after irradiation are substantially the same (variations are within the experimental errors; see Tables 1 and 2). This result again confirms that nanostructured $\mathrm{ZnO}$ displays a photoprotecting action towards both wood and organic coating.

3.4. Microbiology Test. Among the fungi occurring on trees, wood decay fungi are considered an important source of damage to both living trees and wood artifacts. The growth of common fungal species, i.e., mold, on the surface of untreated and treated maple specimens was investigated in order to assess the possible contribution of nanostructured $\mathrm{ZnO}$ to increasing the wood resistance toward this biodegradation agent.

Mold growth was investigated by exposing watersaturated specimens ( $\mathrm{UW}, \mathrm{W}+\mathrm{ZnO}, \mathrm{W}+\mathrm{SH}$, and $\mathrm{W}+\mathrm{ZnO}$ $+\mathrm{SH}$ ) to controlled ambient conditions (constant relative humidity and temperature, alternate light and dark; see experimental section) and checking for the presence of mold on their surface for 40 days. Optical observations by a digital microscope were performed on a daily basis, while scanning electron microscopy experiments were carried out at the end of the experiment to better characterize the fungal

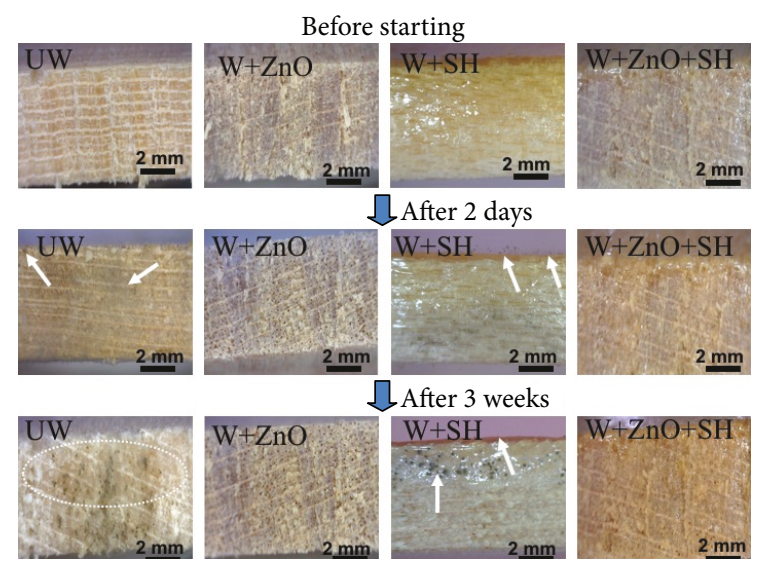

FiguRE 5: Digital microscope images of untreated and coated wood during the fungi test.

microorganisms. Appearance of mold was observed on some areas of untreated maple and, to a lesser extent, of $\mathrm{W}+\mathrm{SH}$ after just two days (Figure 5, white arrows). After 3 weeks, mold covered almost entirely the surface of the UW specimen (Figure 5, white ellipsis) and was quite diffusely present on the surface of $\mathrm{W}+\mathrm{SH}$. On the contrary, the surface of wood specimens treated with $\mathrm{ZnO}$ or with the combination $\mathrm{ZnO}+$ shellac was still free from fungi, even at the end of the experiment, i.e., after 40 days.

SEM micrographs taken on the surface of the investigated specimens after 40 days are reported in Figure 6. Untreated wood is almost uniformly covered with fungal microorganisms, whose morphology can be clearly observed at higher magnification (Figures 6(a) and 6(b)). The surface of $\mathrm{W}+\mathrm{ZnO}$ specimen appears free from mold (Figure 6(c)), and the dense forest of zinc oxide nanorods can be still observed, similarly as the pristine-coated specimen (see Figure 6(d) vs. Figure 2(c)). It confirms the antifungal activity of nanostructured zinc oxide, in accordance with the abovementioned literature data [30-34]. Micrograph taken on $\mathrm{W}+\mathrm{SH}$ shows that mold colonizes even the shellac surface, although to a distinctly lesser extent than untreated maple (Figures 6(e) and 6(f)), suggesting that shellac coating is able to partially inhibit the growth of mold on wood specimens. This behavior may be correlated with the application of shellac-based coatings in food conservation, e.g., to increase the postharvest life of fruit and vegetables, which are highly 


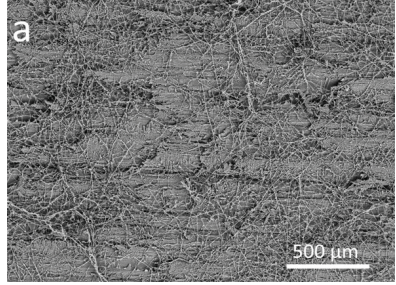

(a)

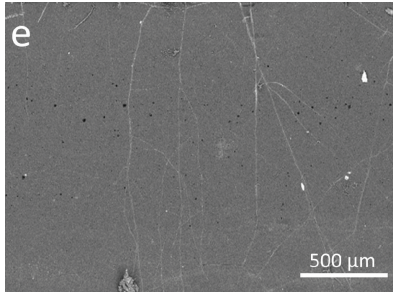

(e)

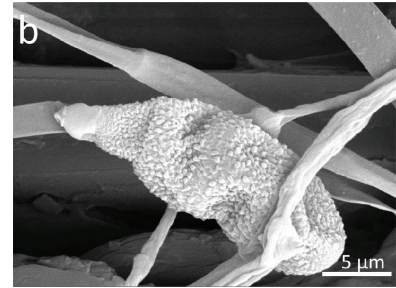

(b)

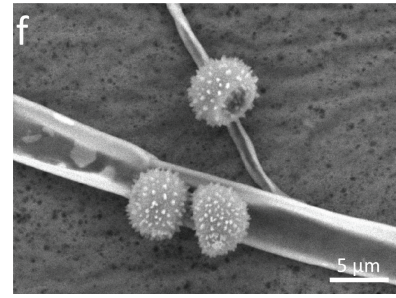

(f)

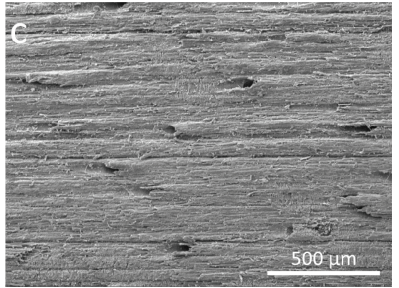

(c)

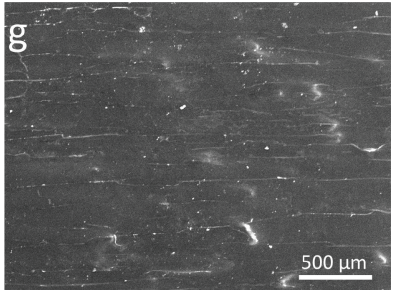

(g)

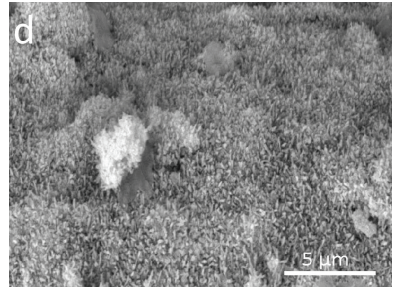

(d)

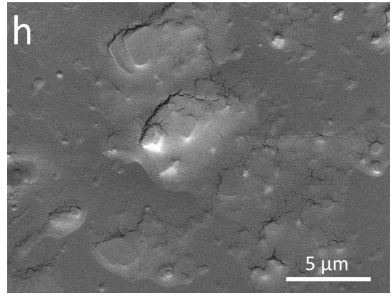

(h)

FIGURE 6: SEM micrographs of wood specimens at the end of the fungi test (after 40 days) with two different magnifications: (a) and (b) UW; (c) and (d) $\mathrm{W}+\mathrm{ZnO}$; (e) and (f) $\mathrm{W}+\mathrm{SH}$; (g) and (h) $\mathrm{W}+\mathrm{ZnO}+\mathrm{SH}$.

susceptible to fungal attack [66]. Wood treated with both $\mathrm{ZnO}$ and shellac shows to be completely resistant to mold growth at the end of the microbiology test, i.e., after 40 days: in fact, no fungal microorganism has been detected on its surface although the nanosized $\mathrm{ZnO}$ is completely covered by shellac film. This seems quite surprising as the antifungal effect of $\mathrm{ZnO}$ is effective even when covered with a quite homogeneous shellac layer. Antimicrobial activity without any apparent contact of $\mathrm{ZnO}$ with fungal cells cannot be easily explained on the basis of the different abovementioned mechanisms (see Section 1, [30-34]). Therefore, further studies will be needed in order to better clarify the antifungal mechanism of nanostructured $\mathrm{ZnO}$, which is active against fungi even when covered by an organic coating film.

At any rate, these results indicate that consecutive application of nanostructured $\mathrm{ZnO}$ and shellac on wood provides a "combined" protecting effect from fungi proliferation: organic coating acts as a barrier that slows down the growth of mold by avoiding its contact with wood surface; zinc oxide nanoparticles behave as toxic agent against microbial cells [67] and prevent fungal growth even if shellac coating should fail (e.g., occasional anomalies of the coating film, scratches due to mechanical wear, and cracking induced by decay of organic resin).

\section{Conclusions}

In this work, the protective effects induced by the consecutive applications of nanostructured $\mathrm{ZnO}$ and shellac varnish on the surface of maple wood have been investigated. A quite homogeneous layer of nanosized crystalline $\mathrm{ZnO}$ can be produced on the wood surface by a two-step hydrothermal procedure. This nanostructured material relevantly increases the resistance of maple wood to UV-induced ageing, as expected on the basis of previous literature works. An enhancement of the resistance to the growth of common fungal agents, i.e. mold, is also provided by this treatment.
The increased protecting ability from photodegradation and fungi biodeterioration exhibited by nanostructured $\mathrm{ZnO}$ is preserved after covering it with shellac coating, which is largely used as a finish for wooden artifacts.

A previous study [15] showed that $\mathrm{ZnO}$ nanoparticles dispersed into the shellac matrix improve the resistance of the varnish layer to the UV-induced degradation. Nevertheless, the nanoparticles' mobility into the coating matrix cannot be prevented and aggregation process can take place after some time, with consequent loss of most protecting effectiveness of the nanocomposite. In the present work, $\mathrm{ZnO}$ nanoparticles are anchored to the wood surface and can carry out their protecting activity not only towards the wood but also toward the shellac varnish.

In conclusion, the consecutive application of nanostructured zinc oxide and shellac varnish on wood surface can be considered an interesting and promising protecting treatment for wooden materials, since it combines the aesthetical and water-repellant features of the traditional shellac finish with the excellent properties of inorganic nanoparticles, which enhance the resistance towards decay induced by light and fungal agents.

\section{Data Availability}

The data used to support the findings of this study are included within the article.

\section{Conflicts of Interest}

The authors declare that they have no conflicts of interest.

\section{References}

[1] P. Evans, "Emerging technologies in wood protection," Forest Products Journal, vol. 53, no. 1, pp. 14-22, 2003.

[2] T. Shupe, S. Lebow, and D. Ring, "Causes and control of wood decay, degradation \& stain," in Degradation \& Stain. Pub. 
(Louisiana Cooperative Extension Service) -2703, Louisiana State University Agricultural Center, Baton Rouge, La., 2008.

[3] K. K. Pandey, "Study of the effect of photo-irradiation on the surface chemistry of wood," Polymer Degradation and Stability, vol. 90, no. 1, pp. 9-20, 2005.

[4] D. N. S. Hon, "Photochemistry of wood," in Wood and Cellulosic Chemistry, D. N. S. Hon and N. Shiraishi, Eds., pp. 525-555, Marcel Decker, 1991.

[5] Q. Sun, Y. Lu, H. Zhang et al., "Improved UV resistance in wood through the hydrothermal growth of highly ordered ZnO nanorod arrays," Journal of Materials Science, vol. 47, no. 10, pp. 4457-4462, 2012.

[6] P. Nzokou, D. P. Kamdem, and A. Temiz, "Effect of accelerated weathering on discoloration and roughness of finished ash wood surfaces in comparison with red oak and hard maple," Progress in Organic Coatings, vol. 71, no. 4, pp. 350-354, 2011.

[7] S. Zahri, C. Belloncle, F. Charrier, P. Pardon, S. Quideau, and B. Charrier, "UV light impact on ellagitannins and wood surface colour of European oak (Quercus petraea and Quercus robur)," Applied Surface Science, vol. 253, no. 11, pp. 4985-4989, 2007.

[8] M.-1. Kuo and N. Hu, "Ultrastructural changes of photodegradation of wood surfaces exposed to UV," Holzforschung, vol. 45, no. 5, pp. 347-353, 1991.

[9] R. Giorgi, D. Chelazzi, and P. Baglioni, "Nanoparticles of calcium hydroxide for wood conservation. The deacidification of the vasa warship," Langmuir, vol. 21, no. 23, pp. 1074310748, 2005.

[10] M. V. Cristea, B. Riedl, and P. Blanchet, "Effect of addition of nanosized UV absorbers on the physico-mechanical and thermal properties of an exterior waterborne stain for wood," Progress in Organic Coatings, vol. 72, no. 4, pp. 755-762, 2011.

[11] N. Auclair, B. Riedl, V. Blanchard, and P. Blanchet, "Improvement of photoprotection of wood coatings by using inorganic nanoparticles as ultraviolet absorbers," Forest Products Journal, vol. 61, no. 1, pp. 20-27, 2011.

[12] M. Vlad-Cristea, B. Riedl, P. Blanchet, and E. Jimenez-Pique, "Nanocharacterization techniques for investigating the durability of wood coatings," European Polymer Journal, vol. 48, no. 3, pp. 441-453, 2012.

[13] J. Salla, K. K. Pandey, and K. Srinivas, "Improvement of UV resistance of wood surfaces by using $\mathrm{ZnO}$ nanoparticles," Polymer Degradation and Stability, vol. 97, no. 4, pp. 592-596, 2012.

[14] M. S. Lowry, D. R. Hubble, A. L. Wressell, M. S. Vratsanos, F. R. Pepe, and C. R. Hegedus, "Assessment of UVpermeability in nano- $\mathrm{ZnO}$ filled coatings via high throughput experimentation," Journal of Coatings Technology and Research, vol. 5, no. 2, pp. 233-239, 2008.

[15] M. L. Weththimuni, D. Capsoni, M. Malagodi, C. Milanese, and M. Licchelli, "Shellac/nanoparticles dispersions as protective materials for wood," Applied Physics A, vol. 122, no. 12, 2016.

[16] N. S. Allen, M. Edge, A. Ortega et al., "Degradation and stabilisation of polymers and coatings: nano versus pigmentary titania particles," Polymer Degradation and Stability, vol. 85, no. 3, pp. 927-946, 2004.

[17] S. K. Dhoke, R. Bhandari, and A. S. Khanna, "Effect of nano- $\mathrm{ZnO}$ addition on the silicone-modified alkyd-based waterborne coatings on its mechanical and heat-resistance properties," Progress in Organic Coatings, vol. 64, no. 1, pp. 39-46, 2009.

[18] E. Amerio, P. Fabbri, G. Malucelli, M. Messori, M. Sangermano, and R. Taurino, "Scratch resistance of nano-silica reinforced acrylic coatings," Progress in Organic Coatings, vol. 62, no. 2, pp. 129-133, 2008.

[19] C. Sow, B. Riedl, and P. Blanchet, "UV-waterborne polyurethane-acrylate nanocomposite coatings containing alumina and silica nanoparticles for wood: mechanical, optical, and thermal properties assessment," Journal of Coatings Technology and Research, vol. 8, no. 2, pp. 211-221, 2011.

[20] Y. Yu, Z. Jiang, G. Wang, and Y. Song, "Growth of ZnO nanofilms on wood with improved photostability," Holzforschung, vol. 64 , no. 3, 2010.

[21] G. Rassam, Y. Abdi, and A. Abdi, "Deposition of TiO2nanoparticles on wood surfaces for UV and moisture protection," Journal of Experimental Nanoscience, vol. 7, no. 4, pp. 468476, 2012

[22] F. Weichelt, R. Emmler, R. Flyunt, E. Beyer, M. R. Buchmeiser, and M. Beyer, "ZnO-based UV nanocomposites for wood coatings in outdoor applications," Macromolecular Materials and Engineering, vol. 295, no. 2, p. NA, 2009.

[23] F. Chen, X. Yang, and Q. Wu, "Antifungal capability of $\mathrm{TiO}_{2}$ coated film on moist wood," Building and Environment, vol. 44, no. 5, pp. 1088-1093, 2009.

[24] A. Dev, R. Niepelt, J. P. Richters, C. Ronning, and T. Voss, "Stable enhancement of near-band-edge emission of $\mathrm{ZnO}$ nanowires by hydrogen incorporation," Nanotechnology, vol. 21, no. 6, p. 065709, 2010.

[25] C. H. Lin, B.-S. Chiou, C. H. Chang, and J. D. Lin, "Preparation and cathodoluminescence of $\mathrm{ZnO}$ phosphor," Materials Chemistry and Physics, vol. 77, no. 3, pp. 647-654, 2003.

[26] W. Jun, X. Changsheng, B. Zikui, Z. Bailin, H. Kaijin, and W. Run, "Preparation of $\mathrm{ZnO}$-glass varistor from tetrapod $\mathrm{ZnO}$ nanopowders," Materials Science and Engineering B, vol. 95, no. 2, pp. 157-161, 2002.

[27] J. Xu, Y.'a. Shun, Q. Pan, and J. Qin, “Sensing characteristics of double layer film of $\mathrm{ZnO}$," Sensors and Actuators B-Chemical, vol. 66, no. 1-3, pp. 161-163, 2000.

[28] B. Tigges, M. Moller, and O. Weichold, " $\mathrm{ZnO}$ nanoparticlecontaining emulsions for transparent, hydrophobic UVabsorbent films," Journal of Colloid and Interface Science, vol. 345, no. 1, pp. 41-45, 2010.

[29] A. Becheri, M. Dürr, P. Lo Nostro, and P. Baglioni, "Synthesis and characterization of zinc oxide nanoparticles: application to textiles as UV-absorbers," Journal of Nanoparticle Research, vol. 10, no. 4, pp. 679-689, 2008.

[30] L. He, Y. Liu, A. Mustapha, and M. Lin, "Antifungal activity of zinc oxide nanoparticles against Botrytis cinerea and Penicillium expansum," Microbiological Research, vol. 166, no. 3, pp. 207-215, 2011

[31] X. Wang, F. Yang, W. Yang, and X. Yang, "A study on the antibacterial activity of one-dimensional $\mathrm{ZnO}$ nanowire arrays: effects of the orientation and plane surface," Chemical Communications, vol. 42, no. 42, pp. 4419-4421, 2007.

[32] D. Sharma, J. Rajput, B. S. Kaith, M. Kaur, and S. Sharma, "Synthesis of $\mathrm{ZnO}$ nanoparticles and study of their antibacterial and antifungal properties," Thin Solid Films, vol. 519, no. 3, pp. 1224-1229, 2010.

[33] P. Patra, S. Mitra, N. Debnath, and A. Goswami, "Biochemical, biophysical-, and microarray-based antifungal evaluation of 
the buffer-mediated synthesized Nano zinc oxide: an in vivo and in vitro toxicity study," Langmuir, vol. 28, no. 49, pp. 16966-16978, 2012.

[34] A. Sirelkhatim, S. Mahmud, A. Seeni et al., "Review on zinc oxide nanoparticles: antibacterial activity and toxicity mechanism," Nano-Micro Letters, vol. 7, no. 3, pp. 219-242, 2015.

[35] T. Shupe, C. Piao, and C. Lucas, "The termiticidal properties of superhydrophobic wood surfaces treated with ZnO nanorods," European Journal of Wood and Wood Products, vol. 70, no. 4, pp. 531-535, 2012.

[36] A. John, H. U. Ko, D. G. Kim, and J. Kim, "Preparation of cellulose-ZnO hybrid films by a wet chemical method and their characterization," Cellulose, vol. 18, no. 3, pp. 675-680, 2011.

[37] G. Mantanis, E. Terzi, S. N. Kartal, and A. N. Papadopoulos, "Evaluation of mould, decay and termite resistance of pine wood treated with zinc- and copper-based nanocompounds," International Biodeterioration \& Biodegradation, vol. 90, pp. 140-144, 2014.

[38] H. Wang, A. Zakirov, S. U. Yuldashev, J. Lee, D. Fu, and T. Kang, "ZnO films grown on cotton fibers surface at low temperature by a simple two-step process," Materials Letters, vol. 65, no. 9, pp. 1316-1318, 2011.

[39] C. A. Clausen, V. W. Wang, R. A. Arango, and F. Green, "Feasibility of nanozinc oxide as a wood preservative," Proceedings of American Wood Protection Association, vol. 105, pp. 255260, 2009.

[40] A. Spinella, M. Malagodi, M. L. Saladino, M. L. Weththimuni, E. Caponetti, and M. Licchelli, "A step forward in disclosing the secret of Stradivari's varnish by NMR spectroscopy," Journal of Polymer Science, Part A: Polymer Chemistry, vol. 55, no. 23, pp. 3949-3954, 2017.

[41] P. K. Bose, Y. Sankaranarayanan, and S. C. Sengupta, Chemistry of Lac, vol. 1, Indian Lac Research Institute, Ranchi, 1963.

[42] M. Licchelli, M. Malagodi, M. Somaini, M. Weththimuni, and C. Zanchi, "Surface treatments of wood by chemically modified shellac," Surface Engineering, vol. 29, no. 2, pp. 121-127, 2013.

[43] Y. Yu, Z. Jiang, G. Wang, G. Tian, H. Wang, and Y. Song, "Surface functionalization of bamboo with nanostructured $\mathrm{ZnO}$," Wood Science and Technology, vol. 46, no. 4, pp. 781-790, 2012.

[44] UNI EN 15886: 2010, Conservazione dei Beni Culturali Metodi di prova - Misura del colore delle superfici, UNI Ente Italiano di Normazione, 2010.

[45] L. Vayssieres, K. Keis, A. Hagfeldt, and S.-E. Lindquist, "Three-dimensional array of highly oriented crystalline ZnO microtubes," Chemistry of Materials, vol. 13, no. 12, pp. 4395-4398, 2001.

[46] L. Schmidt-Mende and J. L. MacManus-Driscoll, "ZnO nanostructures, defects, and devices," Materials Today, vol. 10 , no. 5 , pp. $40-48,2007$.

[47] M. N. R. Ashfold, R. P. Doherty, N. G. Ndifor-Angwafor, D. J. Riley, and Y. Sun, "The kinetics of the hydrothermal growth of $\mathrm{ZnO}$ nanostructures," Thin Solid Films, vol. 515, no. 24, pp. 8679-8683, 2007.

[48] H. J. Jung, S. Lee, Y. Yu, S. M. Hong, H. C. Choi, and M. Y. Choi, "Low-temperature hydrothermal growth of $\mathrm{ZnO}$ nanorods on sol-gel prepared $\mathrm{ZnO}$ seed layers: optimal growth conditions," Thin Solid Films, vol. 524, pp. 144-150, 2012.
[49] Y. Tong, Y. Liu, L. Dong et al., "Growth of $\mathrm{ZnO}$ nanostructures with different morphologies by using hydrothermal technique," The Journal of Physical Chemistry B, vol. 110, no. 41, pp. 20263-20267, 2006.

[50] S. Boubenia, A. S. Dahiya, G. Poulin-Vittrant, F. Morini, K. Nadaud, and D. Alquier, "A facile hydrothermal approach for the density tunable growth of $\mathrm{ZnO}$ nanowires and their electrical characterizations," Scientific Reports, vol. 7, no. 1, 2017.

[51] S. Xu, C. Lao, B. Weintraub, and Z. L. Wang, "Densitycontrolled growth of aligned $\mathrm{ZnO}$ nanowire arrays by seedless chemical approach on smooth surfaces," Journal of Materials Research, vol. 23, no. 08, pp. 2072-2077, 2008.

[52] K. Edalati, A. Shakiba, J. Vahdati-Khaki, and S. M. Zebarjad, "Low-temperature hydrothermal synthesis of $\mathrm{ZnO}$ nanorods: effects of zinc salt concentration, various solvents and alkaline mineralizers," Materials Research Bulletin, vol. 74, pp. 374379, 2016.

[53] R. Shi, P. Yang, X. Dong, Q. Ma, and A. Zhang, "Growth of flower-like $\mathrm{ZnO}$ on $\mathrm{ZnO}$ nanorod arrays created on zinc substrate through low-temperature hydrothermal synthesis," Applied Surface Science, vol. 264, pp. 162-170, 2013.

[54] S. Baruah and J. Dutta, "pH-dependent growth of zinc oxide nanorods," Journal of Crystal Growth, vol. 311, no. 8, pp. 2549-2554, 2009.

[55] L. E. Greene, M. Law, J. Goldberger et al., "Low-temperature wafer-scale production of $\mathrm{ZnO}$ nanowire arrays," Angewandte Chemie, vol. 115, no. 26, pp. 3139-3142, 2003.

[56] C. Pacholski, A. Kornowski, and H. Weller, "Self-assembly of $\mathrm{ZnO}$ : from nanodots to nanorods," Angewandte Chemie International Edition, vol. 41, no. 7, pp. 11881191, 2002.

[57] C. Wang, C. Piao, and C. Lucas, "Synthesis and characterization of superhydrophobic wood surfaces," Journal of Applied Polymer Science, vol. 119, no. 3, pp. 1667-1672, 2011.

[58] S. Baruah and J. Dutta, "Hydrothermal growth of $\mathrm{ZnO}$ nanostructures," Science and technology of advanced materials, vol. 10, no. 1, p. 013001, 2009.

[59] A. Sugunan, H. C. Warad, M. Boman, and J. Dutta, "Zinc oxide nanowires in chemical bath on seeded substrates: role of hexamine," Journal of Sol-Gel Science and Technology, vol. 39, no. 1, pp. 49-56, 2006.

[60] V. Khranovskyy, T. Ekblad, R. Yakimova, and L. Hultman, "Surface morphology effects on the light-controlled wettability of $\mathrm{ZnO}$ nanostructures," Applied Surface Science, vol. 258, no. 20, pp. 8146-8152, 2012.

[61] B. Mohebby, "Application of ATR infrared spectroscopy in wood acetylation," Journal of Agricultural Science and Technology, vol. 10, no. 3, pp. 253-259, 2008.

[62] S. Limmatvapirat, C. Limmatvapirat, S. Puttipipatkhachorn, J. Nuntanid, and M. Luangtana-anan, "Enhanced enteric properties and stability of shellac films through composite salts formation," European Journal of Pharmaceutics and Biopharmaceutics, vol. 67, no. 3, pp. 690-698, 2007.

[63] J. Wang, L. Chen, and Y. He, "Preparation of environmental friendly coatings based on natural shellac modified by diamine and its applications for copper protection," Progress in Organic Coatings, vol. 62, no. 3, pp. 307-312, 2008.

[64] J. Sawai, E. Kawada, F. Kanou et al., "Detection of active oxygen generated from ceramic powders having antibacterial 
activity," Journal of Chemical Engineering of Japan, vol. 29, no. 4, pp. 627-633, 1996.

[65] A. Lipovsky, Z. Tzitrinovich, H. Friedmann, G. Applerot, A. Gedanken, and R. Lubart, "EPR study of visible lightinduced ROS generation by nanoparticles of $\mathrm{ZnO}$," The Journal of Physical Chemistry C, vol. 113, no. 36, pp. 15997-16001, 2009.

[66] K. Chitravathi, O. P. Chauhan, and P. S. Raju, "Postharvest shelf-life extension of green chillies (Capsicum annuum L.) using shellac-based edible surface coatings," Postharvest Biology and Technology, vol. 92, pp. 146-148, 2014.

[67] W. Song, J. Zhang, J. Guo et al., "Role of the dissolved zinc ion and reactive oxygen species in cytotoxicity of $\mathrm{ZnO}$ nanoparticles," Toxicology Letters, vol. 199, no. 3, pp. 389-397, 2010. 


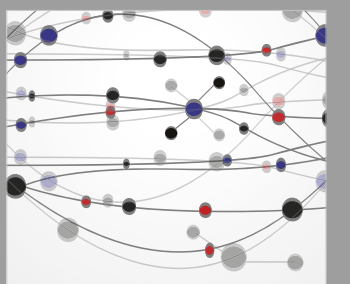

The Scientific World Journal
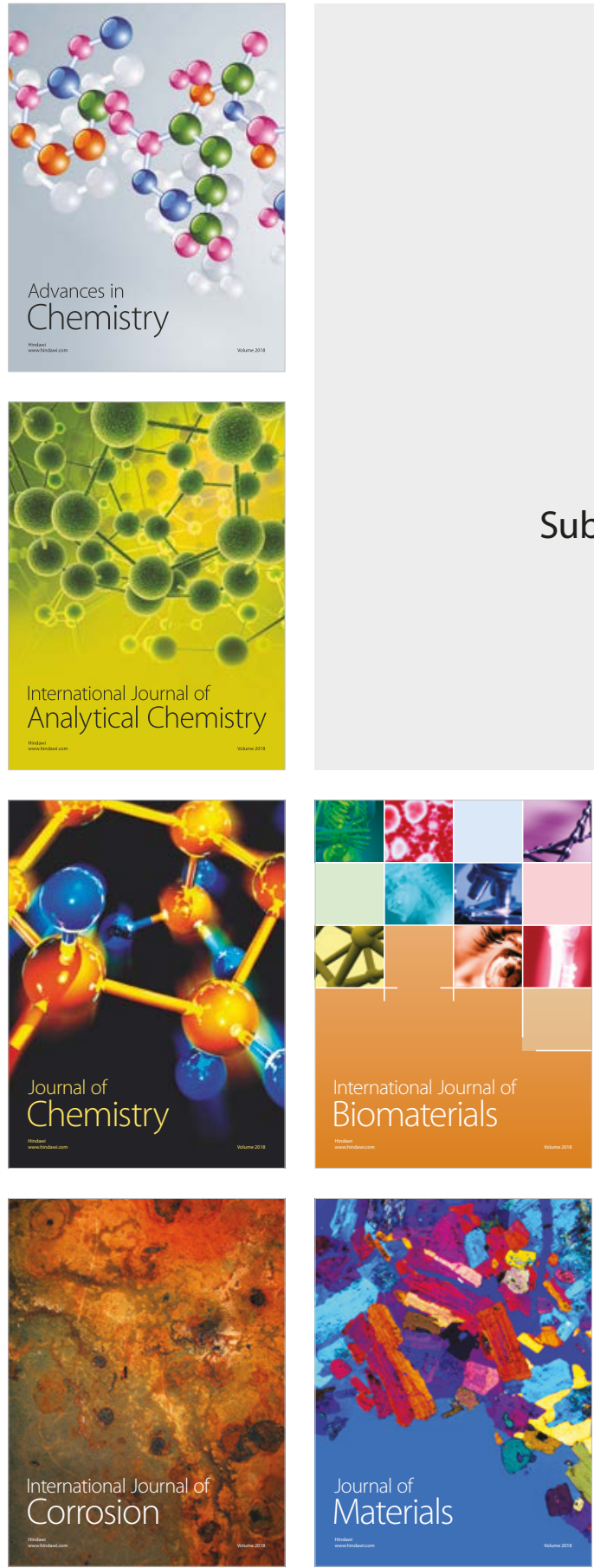

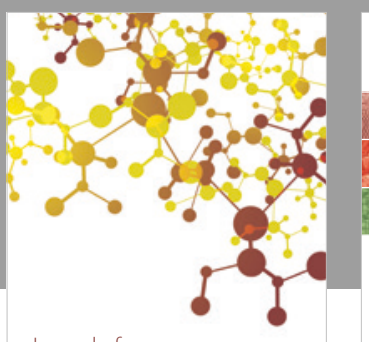

Journal of

Applied Chemistry
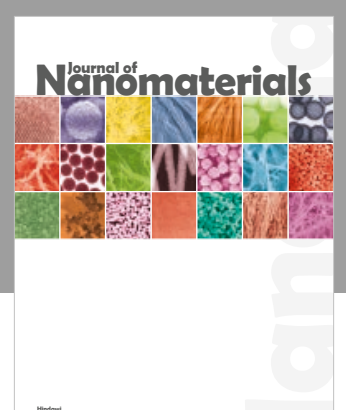

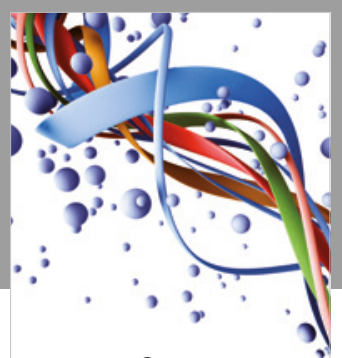

Scientifica

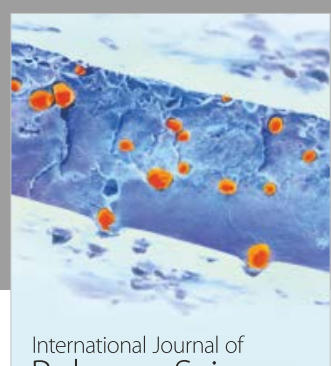

Polymer Science

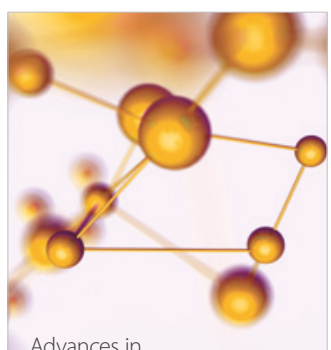

Physical Chemistry
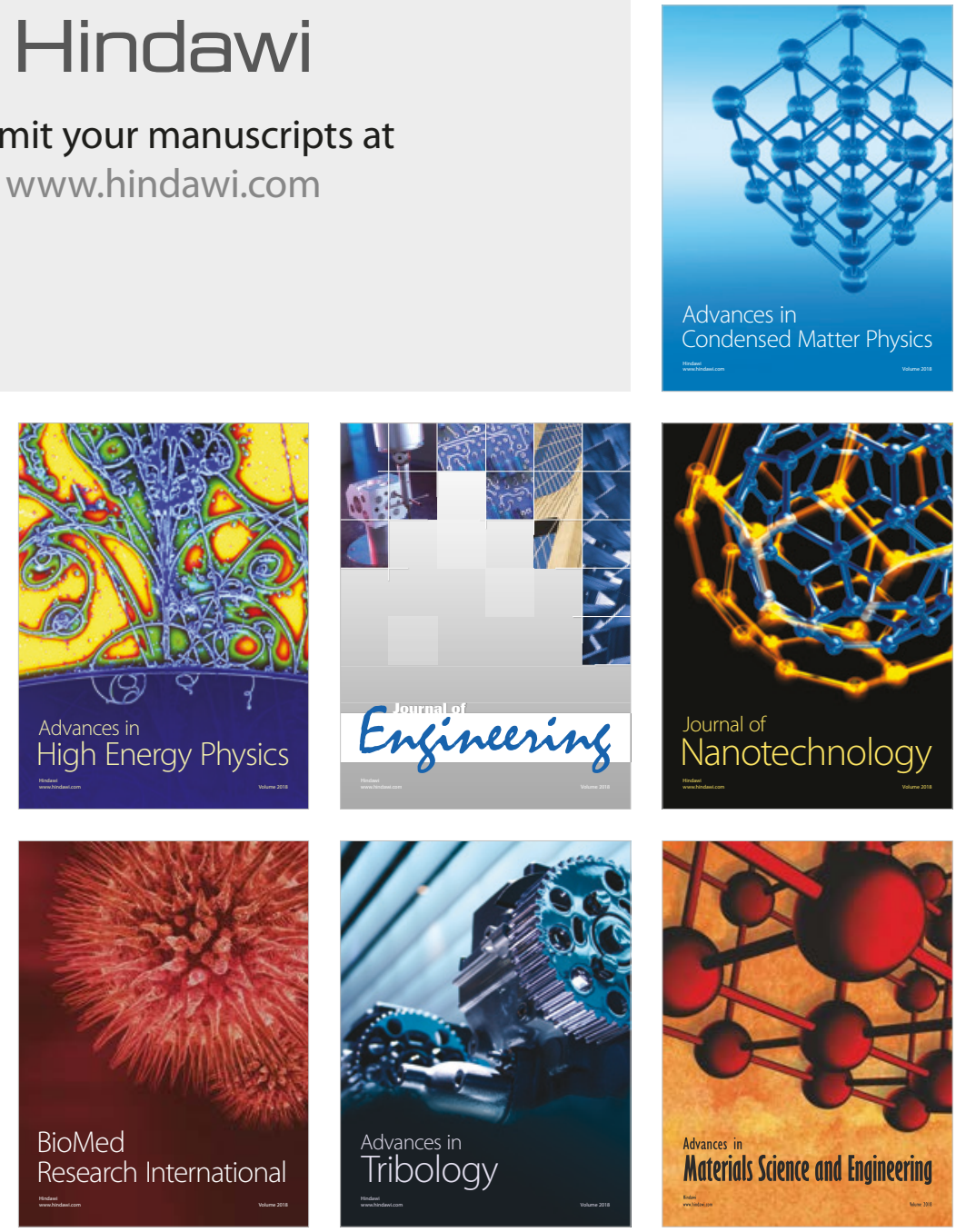